\title{
Functional outcome of contralateral C7 nerve transfer combined with free functional gracilis transplantation to repair total brachial plexus avulsion: a report of thirty-nine cases
}

\author{
Jianping Chen ${ }^{1} \cdot$ Bengang Qin ${ }^{1} \cdot$ Honggang Wang ${ }^{1} \cdot$ Jintao Fang $^{1} \cdot$ Jiantao Yang $^{1}{ }^{(0)} \cdot$ Liqiang Gu $^{1}$
}

Received: 3 November 2020 / Accepted: 4 June 2021 / Published online: 3 February 2022

(c) The Author(s) 2022

\begin{abstract}
Purpose Treatment of total brachial plexus avulsion (TBPA) is a challenge in the clinic, especially the restoration of hand function. The current main surgical order is from proximal to distal joints. The purpose of this study was to demonstrate the outcomes of "distal to proximal" surgical method.

Methods Thirty-nine patients underwent contralateral C7 (CC7) nerve transfer to directly repair the lower trunk (CC7-LT) and phrenic nerve transfer to the suprascapular nerve (PN-SSN) during the first stage, followed by free functional gracilis transplantation (FFGT) for elbow flexion and finger extension. Muscle strength of upper limb, degree of shoulder abduction and elbow flexion, and Semmes-Weinstein monofilament test and static two-point discrimination of the hand were examined according to the modified British Medical Research Council (mBMRC) scoring system.

Results The results showed that motor recovery reached a level of M3 + or greater in $66.7 \%$ of patients for shoulder abduction, $87.2 \%$ of patients for elbow flexion, $48.7 \%$ of patients for finger extension, and $25.6 \%$ of patients for finger flexion. The mean shoulder abduction angle was $45.5^{\circ}$ (range $0-90^{\circ}$ ), and the average elbow flexion angle was $107.2^{\circ}$ (range $0-142^{\circ}$ ), with $2.5 \mathrm{~kg}$ average flexion strength (range $0.5-5 \mathrm{~kg}$ ). In addition, protective sensibility $(\geq \mathrm{S} 2)$ was found to be achieved in $71.8 \%$ of patients.

Conclusion In reconstruction of TBPA, CC7 transfer combined with free functional gracilis transplantation is an available treatment method. It could help patients regain shoulder joint stability and the function of elbow flexion and finger extension and, more importantly, provide finger sensation and partial finger flexion function. However, the pick-up function was unsatisfied, which needed additional surgery.
\end{abstract}

Keywords Contralateral C7 nerve root transfer · Free functional gracilis transplantation · Total brachial plexus avulsion · Function reconstruction $\cdot$ Protective sensibility

\section{Introduction}

Traumatic total brachial plexus avulsion (TBPA) is predominantly present in young adults and results in the complete function loss of the upper extremity. Treatment of TBPA is a challenge because there are limited available donor

Jiantao Yang

truth123811@163.com

Liqiang $\mathrm{Gu}$

guliqiang1963@aliyun.com

1 Department of Orthopedic Trauma and Microsurgery, the First Affiliated Hospital of Sun Yat-Sen University, Guangzhou 510008, China nerves to control the multiple functions that are desirable for the shoulder, elbow, wrist, and hand, and only extraplexal donors can be used [1].

To date, nerve transfer alone or combined with free functional gracilis transplantation (FFGT) is the main options for this irreparable injury. Nerve transfer allows return of some function, but the overall recovery of hand function remains poor [2]. However, FFGT can be used to obtain hand function. In recent years, nerve transfer combined with FFGT or double FFGT was used to restore upper extremity function, especially to improve the hand function[3, 4].

The current surgical order is to restore the elbow flexion and shoulder abduction and followed by wrist and hand function ("proximal to distal") [2, 3, 5]. Based on the clinical research, the shoulder and elbow function of the affected 
limb can be significantly improved [6], but the results of hand function are still poor because of the long distance from the site of injury, the slow rate of nerve regeneration, and muscle denervation $[7,8]$. To improve the results of hand function in the early stage, our team (Professor L.Q. $\mathrm{Gu}$ ) described a "distal to proximal" treatment strategy. In the first stage, we performed CC7-LT to restore the protective sensibility of the hand and finger flexion and PN-SSN to restore shoulder abduction. In the second stage, FFGT was used to reconstruct the elbow flexion and finger extension.

The goal of our study was to evaluate the functional outcomes of CC7-LT and PN-SSN combined with FFGT to repair TBPA.

\section{Patients and methods}

This study was approved by the Ethics Committee of the First Affiliated Hospital of Sun Yat-sen University, China (Application ID: [2019] 397) on November 12, 2019. From January 2006 to December 2016, 43 patients suffering from TBPA, including those with PN palsy (3 patients), underwent subsequent surgery at our institution. All patients were diagnosed by history, physical examination, electrophysiological study, and MRI and confirmed by subsequent intra-operative exploration and neurophysiological investigation. Inclusion criteria were (1) TPBA and (2) followup at least 24 months, and (3) CC7-LT combined with FFGT was the main reconstruction method. Exclusion criteria were (1) diabetes; (2) fracture in the affected upper extremity (1 case); (3) spinal cord injury; (4) brain injury (1 case); (5) distal amputation of injured limb; and (6) refusal to participate. Two patients were lost to follow-up. Finally, 39 patients qualified for this study.

Pre-operative chest radiography and pulmonary function tests were conducted to exclude any pulmonary disease and permit subsequent PN transfer. CT angiography was undertaken to exclude major vascular injury and assess the patency of suitable recipient vessels for FFGT.

\section{Surgical techniques}

All surgical procedures were performed by the same surgeon (L.Q. Gu). In the first stage, details of the surgical techniques have been previously described by Li et al. [9]. The brachial plexus was explored, and the recipient nerves, such as the SSN, lower trunk, or C8T1 nerves, were inspected and prepared. After the $\mathrm{CC} 7$ harvest, it was passed to the injured side through the prespinal route and directly coapted to the lower trunk or C8T1. At the same time, the ipsilateral PN was found on the anterior surface of the scalenus anticus muscle and confirmed by electrical stimulation. The PN (36 patients) was transected as distally as possible and then was directly sutured to SSN using 8-0 Prolene sutures (Fig. 1).

Timing of the second surgery was determined by monthly follow-ups and measurements. Gracilis muscle harvest was done using the technique described by Yang et al. [10]. In this technique, not only the fascia of the gracilis was preserved but also the fascia of the adductor longus and adductor magnus covered the gracilis. Two teams did the surgery simultaneously: One team isolated the donor vessels, the spinal accessory nerve (SAN), and prepared the proximal and distal attachments of the transferred gracilis. The other team harvested the gracilis muscle. Then, the gracilis muscle was proximally sutured to the acromion or the lateral aspect of the clavicle and distally to the extensor digitorum communis in the forearm. This free functional muscle was perfused by the brachial artery, axillary artery, and subclavian artery with T-shaped anastomosis and refluxed by the comitant vein, and it was innervated by the SAN (Fig. 2).

The additional operation depended on whether there were residual roots in the exploration of brachial plexus, the functional recovery of patients, and their wishes. Additional surgery included C5-C6 stump to repair the upper trunk, wrist fusion, thumb reconstruction, tendon transfer, and second gracilis transfer to reconstruct fingers flexion. The second gracilis muscle was placed on the medial aspect of the arm. It was attached proximally to the tendon of the lesser tuberosity of humerus and routed under the lacertus fibrosus, and distally woven into flexor pollicis longus and flexor digitorum profundus. The recipient nerves were the fourth and fifth ICN nerves. The recipient vessels were brachial artery and vein.

All patients were subdivided into group A and group B according to whether they received additional surgery or not. Group A underwent CC7-LT and PN-SSN and FFGT. Group B underwent the same surgery as group A, as well as additional surgery.

\section{Post-operative management}

The patients were immobilized by wearing a head-shoulder custom cast for six weeks after nerve reconstruction. After removing the cast, the patient was sent to the rehabilitation department for training. In the second stage, the patient was also required to wear a cast with anteflexion and adduction of the shoulder, $90^{\circ}$ flexion of the elbow, and finger extension for six weeks. Flap monitoring was performed every hour for the first 48 hours, with a flap colour evaluation and temperature changes using an infrared temperature monitor as parameters [11]. The patient stayed in bed for ten days until the flap survived, and was advised to perform rehabilitation exercises, undergo electrical stimulation therapy, and take neurotrophic drugs after the cast was removed.

\section{Clinical evaluation}

Assessments for this study included clinical measurements of motor and sensory functional recovery. Post-operative functional video assessment was also recorded. Disabilities of the arm, shoulder, and hand (DASH) were scored to 

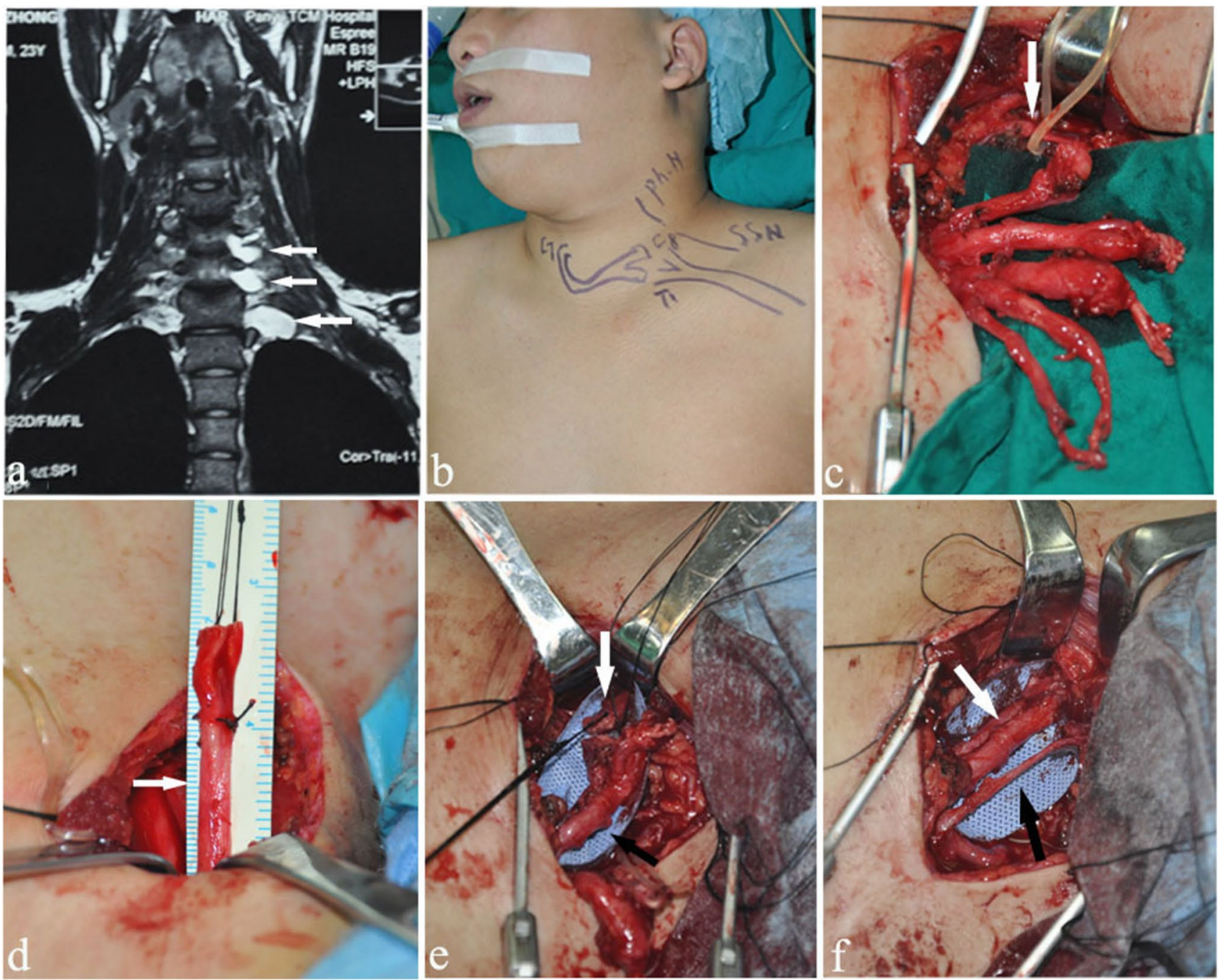

Fig. 1 Intra-operative pictures of the first stage. a Preoperative MRI of the brachial plexus suggested C5-T1 nerve root avulsion with pseudomeningocele formation (white arrow). b Surgical design schematics. c Intra-operative photograph showed the C5-T1 nerve root avulsion and the PN (white arrow). d The CC7 (white arrow) was

assess the function of the injured side [12]. A numeric rating scale (NRS) was used to evaluate pain [13].

\section{Motor function assessment}

The mBMRC grading system [14], with intermediate grades of (-) and ( + ), was used for the motor assessment as follows: Poor, M0 to M2; fair, M2 + to M3; good, M3 + or M4 - ; and excellent, M4 to M5 - . Muscle strength of the injured extremity was measured compared to the normal side. Kilogram lifting was used to assess elbow flexion strength in an anatomically neutral position [15]. When the finger flexion and extension strength reached M3, the pick-up function was measured using a small round object. identified, transected and measured. e There were no gaps between the CC7 (white arrow) and C8T1 (black arrow). f The CC7 was directly coapted to C8T1 (white arrow), and the SSN was simultaneously sutured to the PN (black arrow)

\section{Sensory function assessment}

The sensory of the hand and fingers was assessed by the Semmese-Weinstein monofilament test [16] and static twopoint discrimination (S2PD) [17] and graded according to the mBMRC system. The protective sensibility was graded in $\mathrm{S} 2$.

\section{Statistical analysis}

Descriptive data were expressed as frequencies, and continuous data were presented as the mean and standard deviation or as the mean with a range. Student's unpaired $t$ test was used for the analysis between groups A and B. A value of $<0.05$ was considered statistically significant. 

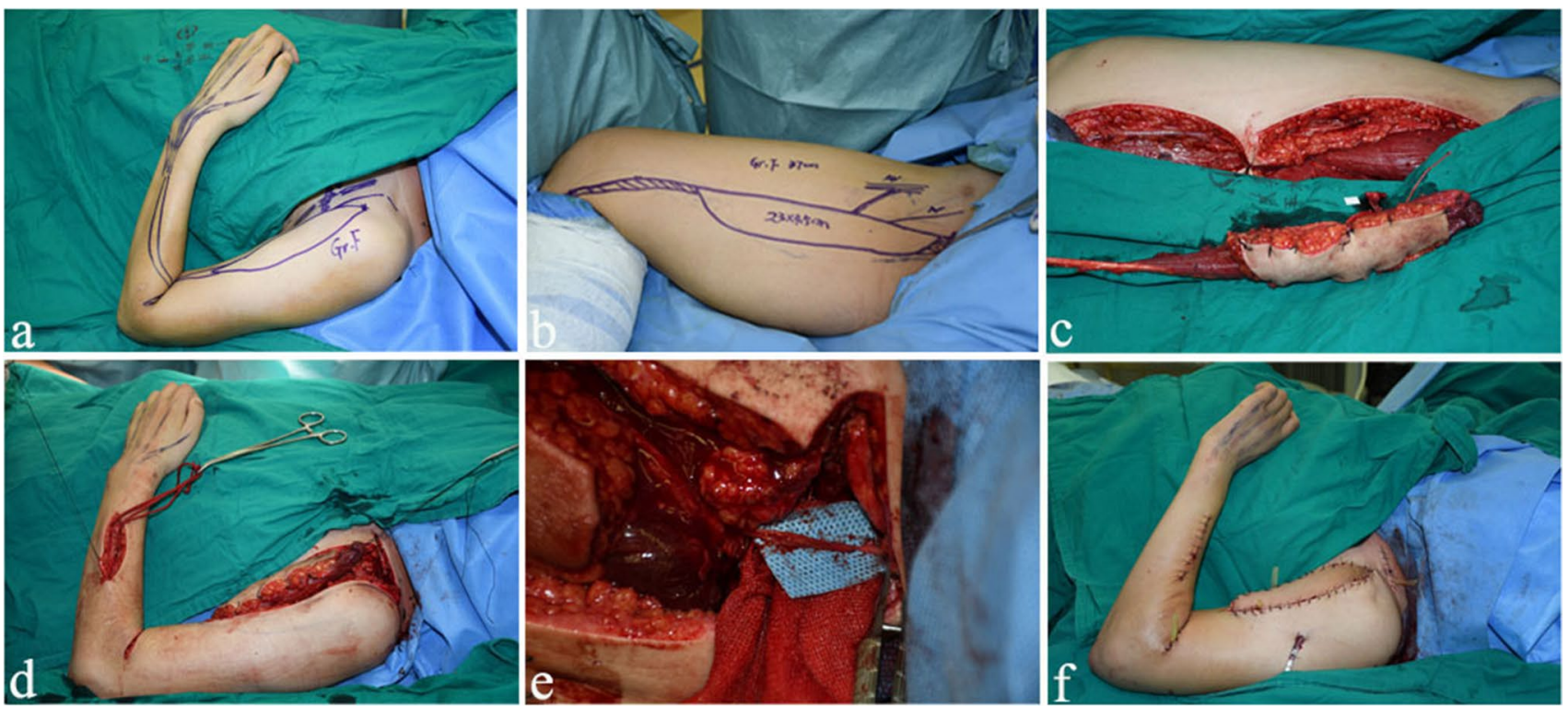

Fig. 2 Intra-operative pictures of the second stage. a Surgical design schematics for the recipient site before operation. b Surgical design schematics for the donor site before operation. c The maximum length of the gracilis muscle was dissected from the thigh. d The

\section{Results}

The demographic characteristics and functional results of the patients are summarized in Tables 1 and 2.

\section{Shoulder function}

PN and proximal stumps were used to restore the shoulder function. At the final follow-up, 35 patients $(89.7 \%)$ recovered shoulder abduction function, with an average angle of $45.5^{\circ}$ (range $0-90^{\circ}$ ); $66.7 \%$ of patients showed good and excellent shoulder abduction strength.

\section{Elbow function}

Thirty-seven patients had successful reconstruction of elbow flexion; no useful elbow flexion was seen in one patient. The average elbow flexion was $107.2^{\circ}$ (range $0-142^{\circ}$ ); $87.0 \%$ of patients had a useful result of M3 + or better, with $2.5 \mathrm{~kg}$ average flexion strength (range $0.5-5 \mathrm{~kg}$ ).

\section{Hand function}

The finger strength is summarized in Table $2.46 .1 \%$ of patients achieved $\geq \mathrm{M} 2+$ for 2 nd -4 th finger flexion, $71.8 \%$ of patients achieved $\geq \mathrm{M} 2+$ for 2 nd-4th finger extension, and nine patients achieved $\geq \mathrm{M} 3$ for finger flexion and extension; only 4 patients regained the pick-up function. All patients showed three gestures as follows: (1) nine patients showed the pick-up gesture, which gracilis was inserted subcutaneously into the anteromedial aspect of the arm. e The nerve of the gracilis was anastomosed to the SAN. f The gracilis muscle maintains a certain tension. A tube was used for drainage after surgery

Table 1 Demographic characteristics and functional results of the 39 patients

\begin{tabular}{|c|c|c|}
\hline Factor & Value & Percentage/mean $\pm \mathrm{SD}$ \\
\hline Male, no & 37 & $94.8 \%$ \\
\hline Female, no & 2 & $5.2 \%$ \\
\hline Left side, no & 26 & $66.7 \%$ \\
\hline Right side, no & 13 & $33.3 \%$ \\
\hline \multicolumn{3}{|l|}{ Cause of injury, no } \\
\hline Car collision & 5 & $12.8 \%$ \\
\hline Motorcycle collision & 21 & $53.8 \%$ \\
\hline Bicycle collision & 1 & $2.6 \%$ \\
\hline $\begin{array}{l}\text { Weight dropping on the } \\
\text { shoulder }\end{array}$ & 2 & $5.2 \%$ \\
\hline Dropping from a height & 7 & $17.9 \%$ \\
\hline $\begin{array}{l}\text { Traction injury of upper } \\
\text { limb }\end{array}$ & 3 & $7.7 \%$ \\
\hline Age of injury, years & $16-49$ & $26.7 \pm 8.7$ \\
\hline $\begin{array}{l}\text { Interval between injury and } \\
\text { op, days }\end{array}$ & $15-210$ & $71.7 \pm 49.4$ \\
\hline $\begin{array}{l}\text { Interval between two stages, } \\
\text { days }\end{array}$ & $104-840$ & $315.8 \pm 180.0$ \\
\hline $\begin{array}{l}\text { Gracilis first construction, } \\
\text { days }\end{array}$ & $120-330$ & $192.5 \pm 49.5$ \\
\hline Follow-up period, mos & $28-169$ & $97 \pm 38.3$ \\
\hline Shoulder abduction $\left(^{\circ}\right)$ & 0-90 & $45.5 \pm 29.0$ \\
\hline Elbow flexion $\left(^{\circ}\right)$ & $0-142$ & $107.2 \pm 30.1$ \\
\hline Elbow flexion strength $(\mathrm{Kg})$ & $0-5$ & $2.5 \pm 1.2$ \\
\hline DASH score & $20-52.5$ & $32.5 \pm 7.1$ \\
\hline NR score & $0-8$ & $4.2 \pm 1.9$ \\
\hline
\end{tabular}




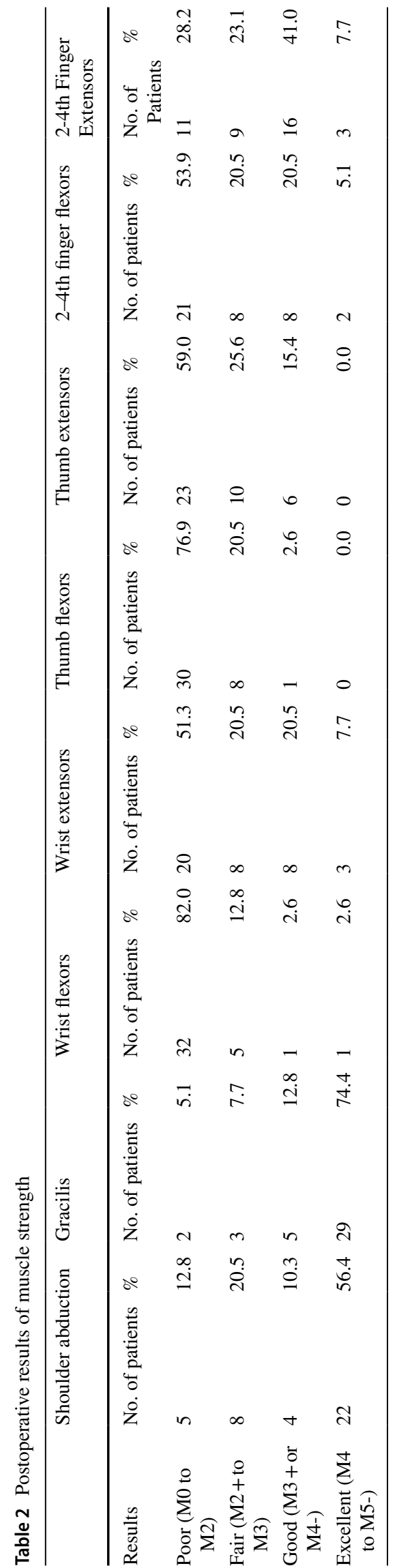

is good for picking up light things (Fig. 3). (2) Twenty patients showed hyperextension of metacarpophalangeal joints (Fig. 4). (3) Ten patients showed a flexion deformity of the middle and distal interphalangeal joints (Fig. 5).

The patients exhibited sensation of the hand and fingers at 14-18 months after operation. Twenty-eight patients (71.8\%) could sense the Semmes-Weinstein monofilament test. Three patients had 4.31, five patients had 4.56, seven patients had 5.07, and 13 patients had 6.65 feeling on monofilament test. Fifteen patients developed an average S2PD sense about $13.5 \mathrm{~mm}$ (range 10-19). According to the mBMRC system, 15 patients (38.5\%) achieved S3 sensory recovery, 13 patients (33.3\%) S2 recovery, and seven patients (18.0\%) S1 recovery. There was no sensory recovery found in four patients (10.2\%), but their sensation could be located in the contralateral hand.

The percentages of no pain, mild, moderate, and severe pain were $5.1 \%, 28.2 \%, 59.0 \%$, and $7.7 \%$, respectively. The average post-operative DASH score was $32.5 \pm 7.1$ (range 20-52.5).

\section{Additional surgery}

Thirteen patients accepted additional surgery in group B. The proximal nerve stumps of seven patients were available in the first stage. Three case of C5-C6 stump were used to repair the upper trunk with a nerve graft, while other four patients had a direct repair. After the two-stage operation, nine patients accepted further surgery to reconstruct the hand function: two wrist fusions, one wrist fusion and tendon transfer, and six secondary gracilis transfers to provide finger flexion. The shoulder abduction angle in group B was significantly better than that in group $\mathrm{A}(\mathrm{P}=0.007)$, and the DASH score in group $\mathrm{B}$ was lower than that in group A $(\mathrm{P}=0.044)$. There were no significant differences in the pain score and elbow flexion degree between the two groups (Table 3).

\section{Complications}

There were some complications in donor side after $\mathrm{CC} 7$ transfer. Twenty-one patients had numbness in the index finger, middle finger, and thumb; this symptom recovered three months later. Ten patients reported elbow extension weakness, but they recovered to normal six months later. Complications in the second stage included venous crisis in two cases (one case survived, the other one removed due to flap necrosis) and one case of thigh haematoma found in the donor area one month later.

\section{Discussion}

Nowadays, most authors reported that the philosophy for TPBA reconstruction was from proximal to distal joints $[2,3$, 5]. They focused on the recovery of limb motor function while 

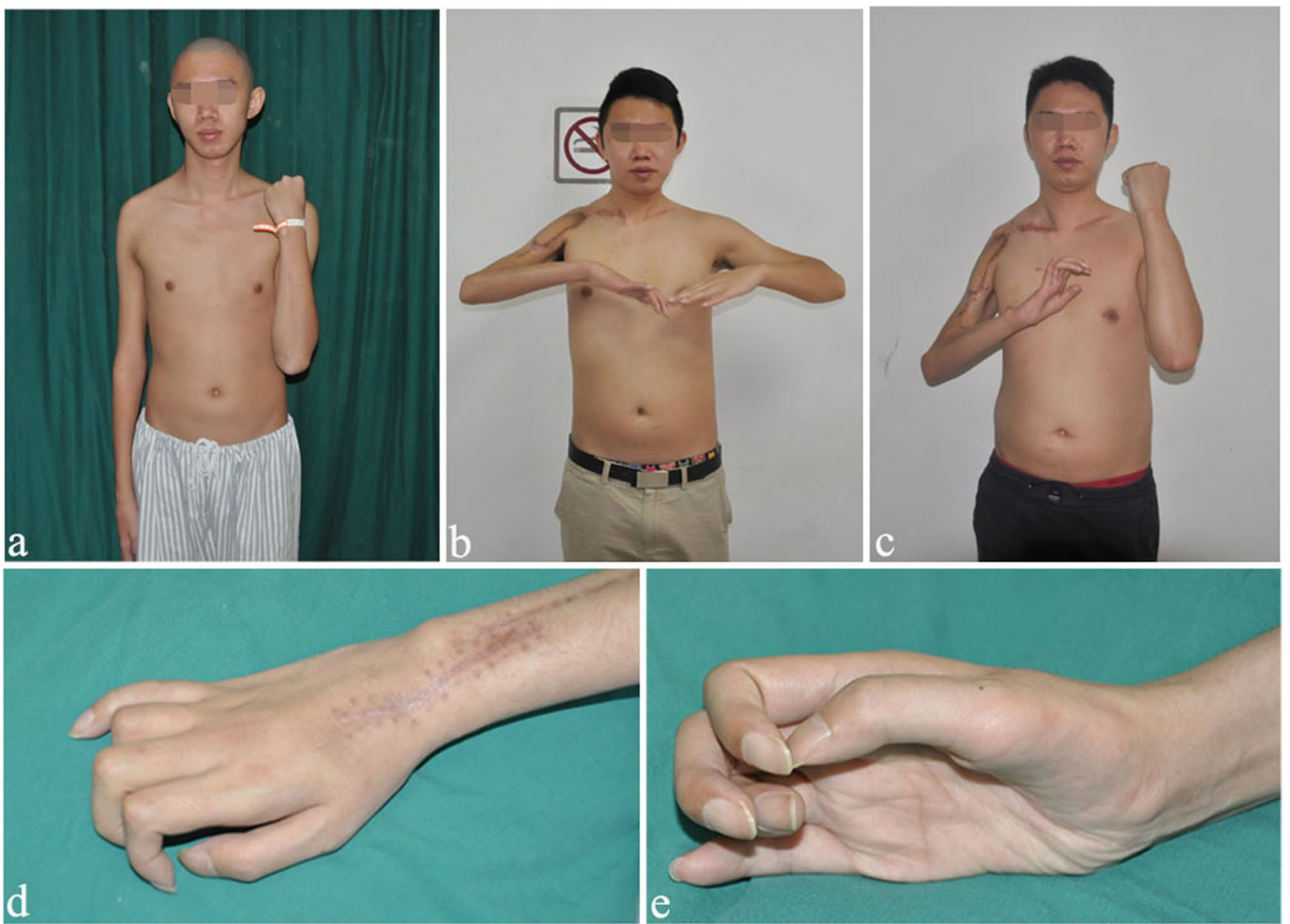

Fig. 3 Case 1: pick-up gesture of the fingers. An 18-year-old man sustained TBPA caused by a motorcycle collision. He underwent three operations: CC7 to LT and PN to SSN, FFGT, and wrist fusion. At the 67-month follow-up, he had regained excellent function of shoulder abduction and elbow flexion. Most importantly, he recovered

ignoring hand sensation. Several studies have confirmed that satisfactory results can be achieved by restoring shoulder and elbow function, but reconstruction of hand function is very challenging. In addition, the injured hand may be further damaged without sensory recovery, particularly by burns in this contact zone [18]. Based on these, our team tries to restore protective sensibility and finger flexion first, followed by the restoration of elbow flexion and finger extension.

Sensation with or without motor function in the hand and shoulder stability has been the usual aims of nerve reconstruction. Since Gu et al. reported the use of CC7 for TBPA, this procedure had been proved to restore the sensory and motor function of the hand [19]. There were several methods for restoring hand function via a CC7 transfer to the lower trunk or the medial nerve with vascularized ulnar nerve bridging. However, related study demonstrated that $\mathrm{CC} 7$ transfer to lower trunk was more effective than to the median nerve in finger flexion [20,21]. The finger flexion results are varied from

the active pick-up function. a Pre-operative view of the right upper limb, which lost the motion and sensory function. b Shoulder abduction and elbow flexion before wrist fusion. c Elbow flexion after wrist fusion. $\mathbf{d}$ and $\mathbf{e}$ Pick-up gesture of the fingers

one centre to another, but the sensory recovery significantly improves. In the literature, the results of finger flexion by $\mathrm{CC} 7$ transfer to the median nerve grade $\geq \mathrm{M} 3$ are approximately 29-34\% [22-24]. A systematic review of CC7 transfer to the median nerve showed that $48 \%$ of patients achieved $\geq \mathrm{M} 3$ wrist flexion, $42 \%$ achieved $\geq$ M3 finger flexion, and 56\% achieved $\geq \mathrm{S} 3$ sensory recovery in the median nerve territories [25]. Bhatia et al. [21] compared two methods for CC7 transfer to the lower trunk: direct repair and nerve graft, the results showed that the finger flexion function of nerve graft group appeared at 16-18 months, a three to six month delay when compared with the direct repair group. In our series, all patients used $\mathrm{CC} 7$ transfer to directly repair the lower trunk or C8T1, avoiding the nerve graft. At the final follow-up, $71.8 \%$ of patients had a recovery of protective sensibility, while $46.1 \%$ of patients achieved grade $\geq \mathrm{M} 3$ finger flexion.

As we know, shoulder stabilization, restoration of abduction, and external rotation are important as more distal 


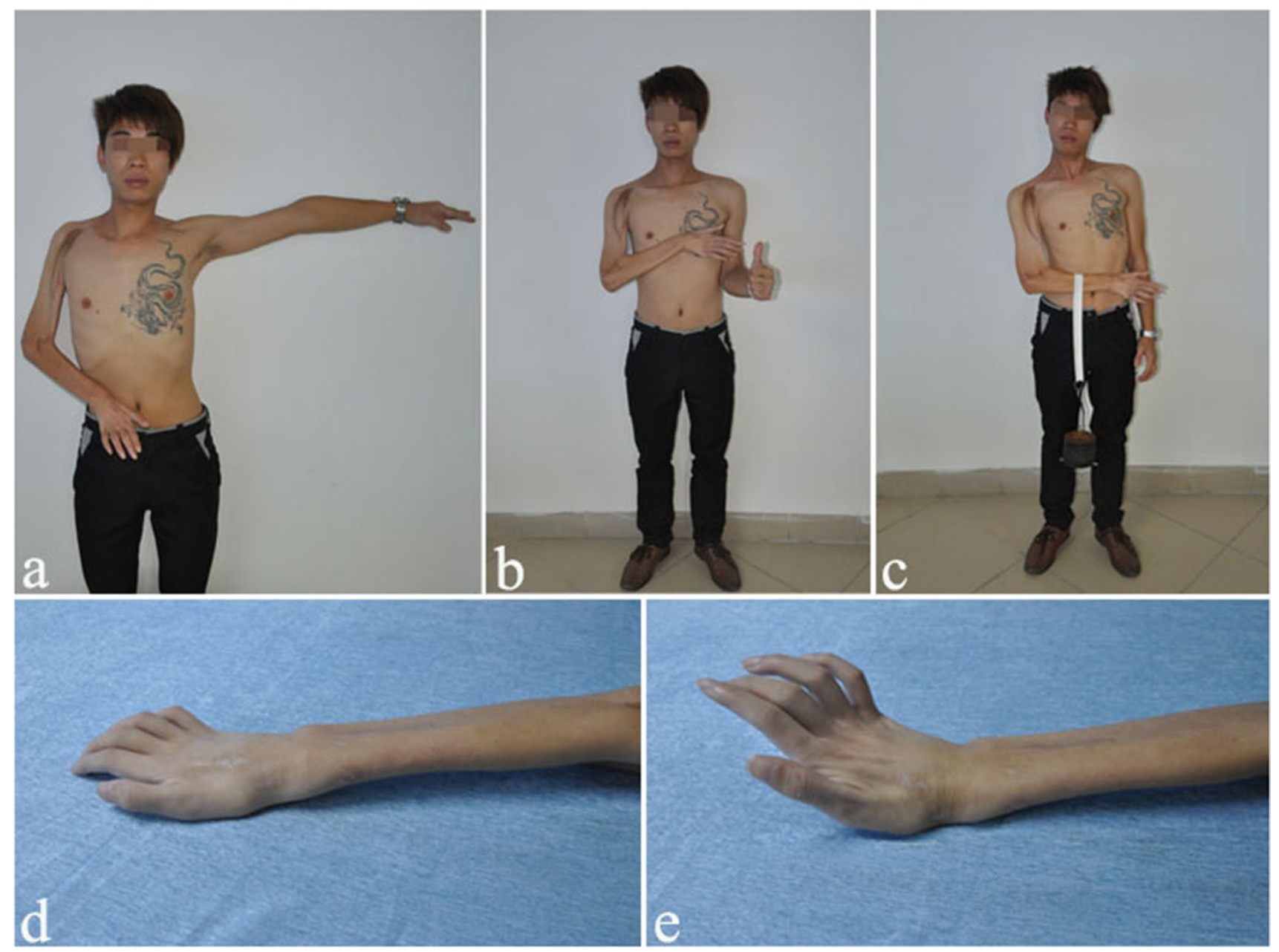

Fig. 4 Case 2: hyperextension of the fingers. A 22-year-old man sustained TBPA and underwent only two operations: CC7 to LT and PN to SSN and FFGT. At the 102-month follow-up, he had regained good muscle strength of elbow flexion and finger extension. His metacarpophalangeal joint showed hyperextension, because the finger exten-

functions will be affected by the condition of the shoulder. To achieve this, various techniques have been proposed and used, such as nerve reconstruction in early stages using intra- or extraplexus donors [26] and secondary procedures including arthrodesis, tendon transfers, and muscle transfers [27-29]. One study showed that when $30^{\circ}$ of shoulder abduction was achieved, shoulder subluxation was usually corrected [30]. In this series, we used PN to SSN and C5-C6 stumps to upper trunk to reconstruct shoulder function. None of the patients performed shoulder fusion because it yielded a poor range of motion. Our results showed that 27 patients $(69.2 \%)$ had a shoulder abduction angle greater than or equal to $30^{\circ}$, and $66.7 \%$ of patients' strength of shoulder abduction showed good and excellent results. Post-operative muscle atrophy was improved, and shoulder subluxation disappeared, specifically for group B patients. But we did not evaluate the shoulder external rotation and forward elevation sion strength (M4-) caused by the gracilis was stronger than the finger flexion strength (M2) restored by the CC7 transfer. a Shoulder abduction. $\mathbf{b}$ and $\mathbf{c}$ Excellent elbow flexion with a strength of $4 \mathrm{~kg}$. $\mathbf{d}$ and $\mathbf{e}$ Wrist and finger extension

because of poor results, so the external rotation needed to further improve by secondary procedures.

Elbow flexion is another important function. Both ICN transfer and FFGT could be used to reconstruct elbow flexion and achieve a good result. In general, FFGT reconstruction achieved better elbow flexion strength than ICN-to-musculocutaneous nerve transfer [31]. Moreover, the gracilis allows for earlier reinnervation and for the restoration of both elbow flexion and finger extension or finger flexion [32]. The SAN and ICN are typically used as donor nerves for the gracilis muscle $[31,33]$. Our team usually used the SAN to reinnervate the first FFGT, and the ICN was used for the second FFGT. A functional elbow range of motion from $30^{\circ}$ to $130^{\circ}$, or active flexion arc of $100^{\circ}$, is required to perform most activities of daily living [34]. In this study, 37 patients achieved elbow flexion recovery, the average elbow flexion degree was $107.2^{\circ}$ (range $0-142^{\circ}$ ), and the average 
Fig. 5 Case 3: hyperflexion of the fingers. A 21-year-old man with TBPA underwent a twostage operation: CC7 to LT and PN to SSN and FFGT. At the 100-month follow-up, he had regained excellent function of elbow flexion and finger flexion. His fingers showed hyperflexion, because the finger flexion strength (M4) restored by CC7 was stronger than the finger extension strength (M2) caused by the gracilis. a Front view after the operation. b Shoulder abduction and elbow flexion. c Elbow flexion with a strength of $5 \mathrm{~kg}$. $\mathbf{d}$ and $\mathbf{e}$ Wrist and finger flexion
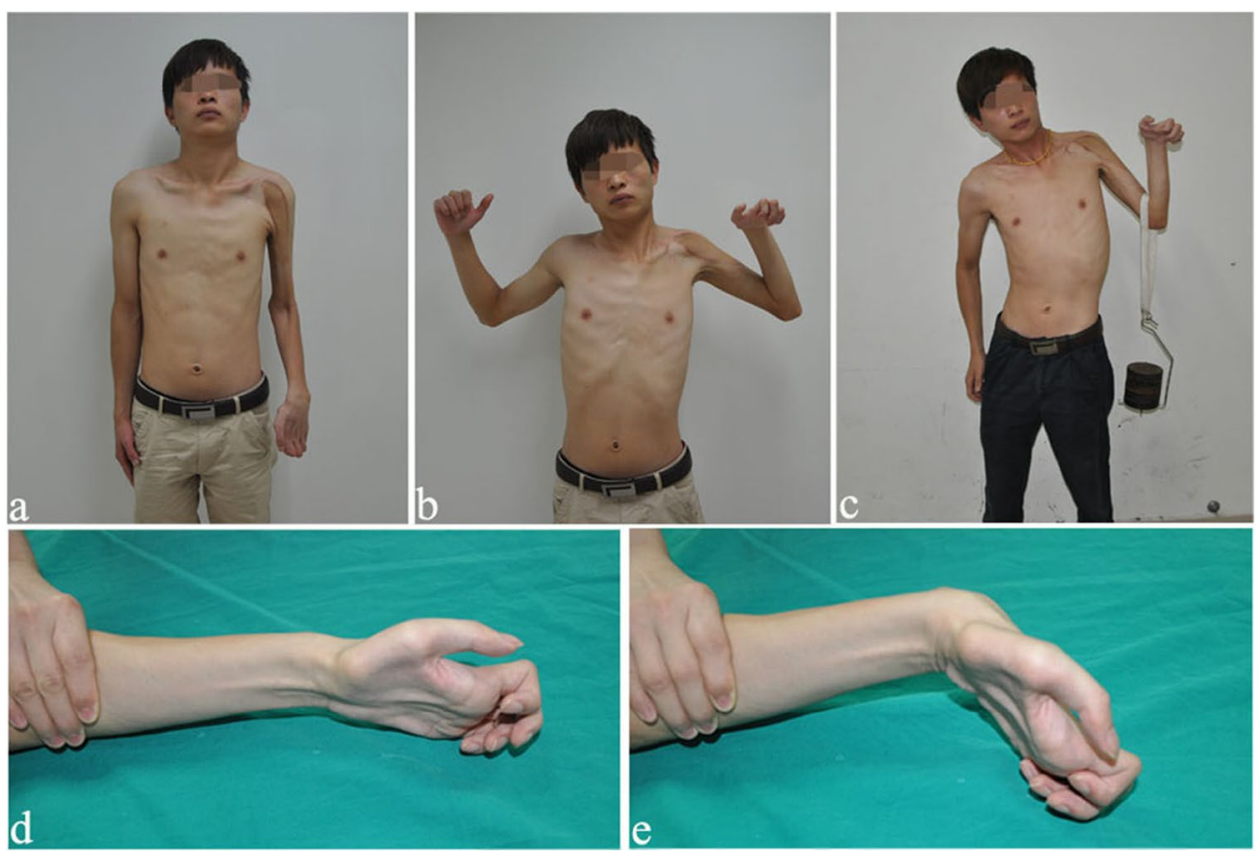

strength was $2.5 \mathrm{~kg}$ (range $0.5-5$ ). These outcomes were superior to those in reports by Coulet [35].

Theoretically, this surgical method is expected to restore the pick-up function. However, the actual results were unsatisfactory; only four patients regained the pick-up function. The patients showed three gestures at the final follow-up, due to the imbalance in the power of the finger flexion CC7 transfer and finger extension gracilis. Most patients showed hyperextension of metacarpophalangeal joints, because the finger extension strength caused by gracilis was stronger than finger flexion strength, or no finger flexion recovery. This study also confirms that the outcome of pick-up function is not satisfactory, even if hand function is repaired early by $\mathrm{CC} 7$ transfer combined FFGT. We think that several factors affect the recovery of pick-up function such as the finger extension strength induced by gracilis was stronger than the finger flexion strength caused by CC7-LT, a long-distance nerve regeneration for the restoration of finger flexion, noncompliance with rehabilitation of patients, and the difficulty and complexity of cerebral cortical reorganization (neuroplasticity). Therefore, further surgery is needed to improve the finger flexion function, such as a second FFGT, tendon transfer, and MCP capsulodesis [36]. Our results are consistent with those reported in the literature that additional surgery can improve hand function and decrease the DASH score [37].

There were several limitations in this study. First, only thirty-nine patients took part in the follow-up research, resulting in a small sample size. Second, this study lacks preoperative DASH and NRS scores of these patients. In general, DASH and NRS scores after the surgery can decrease. Third, TBPA injuries have severe outcomes and lifelong disabilities. While we paid attention to the evaluation of the movement and sensory function of the affected limb, we ignored the assessment of psychology and "return to work".

\section{Conclusions}

In summary, the "distal to proximal" reconstructive method for TBPA is an available method. This technique could help patients improve shoulder joint stability and the function of elbow flexion and finger extension and, more importantly, provide finger sensation and partial finger
Table 3 Comparison of postoperative function and quality of life between group A and group $B$

\begin{tabular}{llll}
\hline Outcome (percentage/mean $\pm \mathrm{SD})$ & Group A & Group B & Unpaired $t$ test $(P)$ \\
\hline Patients number & 26 & 13 & \\
Shoulder abduction $\left(^{\circ}\right)$ & $36.8 \pm 5.6$ & $62.8 \pm 6.0$ & 0.007 \\
Elbow flexion $\left({ }^{\circ}\right)$ & $105.5 \pm 5.4$ & $106.0 \pm 9.6$ & 0.278 \\
Finger flexion $(>\mathrm{M} 3)$ & $30.8 \%(8 / 26)$ & $76.9 \%(10 / 13)$ & 0.007 \\
DASH score & $34.1 \pm 1.5$ & $29.3 \pm 1.4$ & 0.044 \\
NR score & $4.2 \pm 0.4$ & $4.2 \pm 0.4$ & $>0.999$ \\
\hline
\end{tabular}


flexion function to the completely paralytic limb. However, in order to obtain a better pick-up function, patients need additional operations, such as wrist fusion, tendon transfer, and even secondary gracilis transplantation.

Acknowledgements Yi Yang, Wenting He, and Zhehui Tu helped to connect the patients and evaluate the function recovery of them. We would like to give our sincere gratitude to Dr. Yi Yang, Wenting He, and Zhehui Tu from Department of Orthopedic Trauma and Microsurgery, the First Affiliated Hospital of Sun Yat-sen University, Guangzhou, Guangdong, China.

Author contribution Liqiang Gu and Jiantao Yang designed the study. Jianping Chen and Bengang Qin wrote the manuscript. Honggang Wang and Jintao Fang analyzed the data. All authors approved the final version of the paper.

Funding This work was supported by the National Natural Science Foundation of China (grant number 81871787).

Data availability All data gathered can be requested from the corresponding author.

\section{Declarations}

Ethical approval This study was approved by the Ethics Committee of the First Affiliated Hospital of Sun Yat-sen University, China (Application ID: [2019] 397).

Consent for publication All persons gave their informed consent for the publication for the figures and video recordings.

Consent to participate Informed consent was obtained from all individual participants included in the study.

Conflict of interest All authors declare no competing interests.

Open Access This article is licensed under a Creative Commons Attribution 4.0 International License, which permits use, sharing, adaptation, distribution and reproduction in any medium or format, as long as you give appropriate credit to the original author(s) and the source, provide a link to the Creative Commons licence, and indicate if changes were made. The images or other third party material in this article are included in the article's Creative Commons licence, unless indicated otherwise in a credit line to the material. If material is not included in the article's Creative Commons licence and your intended use is not permitted by statutory regulation or exceeds the permitted use, you will need to obtain permission directly from the copyright holder. To view a copy of this licence, visit http://creativecommons.org/licenses/by/4.0/.

\section{References}

1. Doi K (2008) Management of total paralysis of the brachial plexus by the double free-muscle transfer technique. J Hand Surg Eur 33(3):240-251. https://doi.org/10.1177/1753193408090140

2. Bhatia A, Shyam AK, Doshi P, Shah V (2011) Nerve reconstruction: a cohort study of 93 cases of global brachial plexus palsy. Indian J Orthop 45(2):153-160. https://doi.org/10.4103/00195413.77136
3. Chuang DC, Hernon C (2012) Minimum 4-year follow-up on contralateral C7 nerve transfers for brachial plexus injuries. J Hand Surg Am 37(2):270-276. https://doi.org/10.1016/j.jhsa.2011.10. 014

4. Feng J, Wang T, Gu Y et al (2010) Contralateral C7 transfer to lower trunk via a subcutaneous tunnel across the anterior surface of chest and neck for total root avulsion of the brachial plexus: a preliminary report. Neurosurgery 66(6 Suppl):252-263. https:// doi.org/10.1227/01.NEU.0000369658.43380.95

5. Noland SS, Bishop AT, Spinner RJ, Shin AY (2019) Adult traumatic brachial plexus injuries. J Am Acad Orthop Surg 27(19):705-716. https://doi.org/10.5435/JAAOS-D-18-00433

6. Li L, Yang J, Qin B et al (2019) Analysis of human acellular nerve allograft combined with contralateral C7 nerve root transfer for restoration of shoulder abduction and elbow flexion in brachial plexus injury: a mean 4-year follow-up. J Neurosurg 132(6):19141924. https://doi.org/10.3171/2019.2.JNS182620

7. Gutmann E, Young JZ (1944) The re-innervation of muscle after various periods of atrophy. $\mathrm{J}$ Anat $78(\mathrm{Pt} 1-2): 15-43$

8. Sulaiman OA, Gordon T (2009) Role of chronic Schwann cell denervation in poor functional recovery after nerve injuries and experimental strategies to combat it. Neurosurgery 65(4 Suppl):A105-A114. https://doi.org/10.1227/01.NEU.00003 58537.30354.63

9. Li XM, Yang JT, Hou Y et al (2016) Donor-side morbidity after contralateral C-7 nerve transfer: results at a minimum of 6 months after surgery. J Neurosurg 124(5):1434-1441. https://doi.org/10. 3171/2015.3.JNS142213

10. Yang Y, Yang JT, Fu G et al (2016) Functioning free gracilis transfer to reconstruct elbow flexion and quality of life in global brachial plexus injured patients. Sci Rep 6:22479. https://doi.org/ 10.1038/srep22479

11. Estrella EP (2009) An infrared forehead thermometer for flap monitoring. J Plast Reconstr Aesthet Surg 62(6):736. https://doi. org/10.1016/j.bjps.2009.03.002

12. Hudak PL, Amadio PC, Bombardier C (1996) Development of an upper extremity outcome measure: the DASH (Disabilities of the Arm, Shoulder, and Hand) [corrected]. The upper extremity collaborative group (UECG). Am J Ind Med 29(6):602-608. https://doi.org/10.1002/(SICI)1097-0274(199606)29:6\%3c602:: AID-AJIM4\%3e3.0.CO;2-L

13. Flaherty E (2008) Using pain-rating scales with older adults. Am J Nurs 108(6):40-47. https://doi.org/10.1097/01.NAJ.0000324375. 02027.9f

14. Terzis JK, Barmpitsioti A (2012) Our experience with triceps nerve reconstruction in patients with brachial plexus injury. J Plast Reconstr Aesthet Surg 65(5):590-600. https://doi.org/10.1016/j. bjps.2011.11.027

15. Bengtson KA, Spinner RJ, Bishop AT et al (2008) Measuring outcomes in adult brachial plexus reconstruction. Hand Clin 24(4):401-415. https://doi.org/10.1016/j.hcl.2008.04.001

16. Bell-Krotoski JA, Fess EE, Figarola JH, Hiltz D (1995) Threshold detection and Semmes-Weinstein monofilaments. J Hand Ther 8(2):155-162. https://doi.org/10.1016/s0894-1130(12)80314-0

17. Mackinnon SE, Dellon AL (1985) Two-point discrimination tester. J Hand Surg Am 10(6 Pt 1):906-907. https://doi.org/10.1016/ S0363-5023(85)80173-8

18. Bertelli JA, Ghizoni MF (2012) Grafting the C5 root to the musculocutaneous nerve partially restores hand sensation in complete palsies of the brachial plexus. Neurosurgery 71(2):259-263. https://doi.org/10.1227/NEU.0b013e3182571971

19. Gu YD, Zhang GM, Chen DS et al (1992) Seventh cervical nerve root transfer from the contralateral healthy side for treatment of brachial plexus root avulsion. J Hand Surg Br 17(5):518-521. https://doi.org/10.1016/S0266-7681(05)80235-9 
20. Jiang Y, Wang L, Lao J, Zhao X (2018) Total brachial plexus injury: contralateral C7 root transfer to the lower trunk versus the median nerve. Neural Regen Res 13(11):1968-1973. https://doi. org/10.4103/1673-5374.239444

21. Bhatia A, Doshi P, Koul A et al (2017) Contralateral C-7 transfer: is direct repair really superior to grafting? Neurosurg Focus 43(1):E3. https://doi.org/10.3171/2017.4.FOCUS1794

22. Terzis JK, Kokkalis ZT (2009) Selective contralateral C7 transfer in posttraumatic brachial plexus injuries: a report of 56 cases. Plast Reconstr Surg 123(3):927-938. https://doi.org/10.1097/PRS. Ob013e31819ba48a

23. Waikakul S, Orapin S, Vanadurongwan V (1999) Clinical results of contralateral $\mathrm{C} 7$ root neurotization to the median nerve in brachial plexus injuries with total root avulsions. J Hand Surg Br 24(5):556-560. https://doi.org/10.1054/jhsb.1999.0264

24. Songcharoen P, Wongtrakul S, Mahaisavariya B, Spinner RJ (2001) Hemi-contralateral C7 transfer to the median nerve in the treatment of root avulsion brachial plexus injury. J Hand Surg 26(6):1058-1064. https://doi.org/10.1053/jhsu.2001.27764

25. Yang G, Chang KW, Chung KC (2015) A systematic review of contralateral $\mathrm{c} 7$ transfer for the treatment of traumatic brachial plexus injury: Part 1. Overall Outcomes Plast Reconstr Surg 136(4):794-809. https://doi.org/10.1097/PRS.0000000000001494

26. Hardcastle N, Texakalidis P, Nagarajan P et al (2020) Recovery of shoulder abduction in traumatic brachial plexus palsy: a systematic review and meta-analysis of nerve transfer versus nerve graft. Neurosurg Rev 43(3):951-956. https://doi.org/10.1007/ s10143-019-01100-9

27. Valenti P, Werthel JD (2018) Lower trapezius transfer with semitendinosus tendon augmentation: indication, technique, results. Obere Extrem 13(4):261-268. https://doi.org/10.1007/ s11678-018-0495-8

28. Terzis JK, Kostopoulos VK (2010) Free muscle transfer in posttraumatic plexopathies: Part 1. The shoulder Ann Plast Surg 65(3):312-317. https://doi.org/10.1097/SAP.0b013e3181cbfe9d

29. Boe CC, Elhassan BT (2016) Restoration of shoulder function. Hand Clin 32(3):303-310. https://doi.org/10.1016/j.hcl.2016.04. 001
30. Bertelli JA, Ghizoni MF (2007) Transfer of the accessory nerve to the suprascapular nerve in brachial plexus reconstruction. J Hand Surg Am 32(7):989-998. https://doi.org/10.1016/j.jhsa.2007.05. 016

31. Maldonado AA, Kircher MF, Spinner RJ et al (2016) Free functioning gracilis muscle transfer versus intercostal nerve transfer to musculocutaneous nerve for restoration of elbow flexion after traumatic adult brachial pan-plexus injury. Plast Reconstr Surg 138(3):483e-488e. https://doi.org/10.1097/PRS.0000000000 002471

32. Yi Lee TM, Sechachalam S, Satkunanantham M (2019) Systematic review on outcome of free functioning muscle transfers for elbow flexion in brachial plexus injuries. J Hand Surg Eur 44(6):620-627. https://doi.org/10.1177/1753193419825527

33. Cho AB, Bersani Silva G, Pisani MJ et al (2019) Comparison between donor nerves to motorize the free functional gracilis muscle transfer for elbow flexion: Retrospective study of 38 consecutive cases in traumatic adult brachial plexus injuries. Microsurgery 39(5):400-404. https://doi.org/10.1002/micr.30426

34. Morrey BF, Askew LJ, Chao EY (1981) A biomechanical study of normal functional elbow motion. J Bone Joint Surg Am 63(6):872-877

35. Coulet B, Boch C, Boretto J et al (2011) Free gracilis muscle transfer to restore in brachial plexus injuries. Orthop Traumatol Surg Res 97(8):785-792. https://doi.org/10.1016/j.otsr.2011.07. 012

36. Li F, Wang SF, Li PC et al (2018) Restoration of active pick-up function in patients with total brachial plexus avulsion injuries. J Hand Surg Eur 43(3):269-274. https://doi.org/10.1177/17531 93417728405

37. Satbhai NG, Doi K, Hattori Y, Sakamoto S (2016) Functional outcome and quality of life after traumatic total brachial plexus injury treated by nerve transfer or single/double free muscle transfers. Bone Joint J 98-B(2):209-217. https://doi.org/10.1302/0301620X.98B2.35101

Publisher's note Springer Nature remains neutral with regard to jurisdictional claims in published maps and institutional affiliations. 